\title{
On the Embodiment of Economy Principle in the English Language
}

\author{
Guiying Zhou \\ School of Economics and Management, Zhengzhou University of Light Industry \\ No. 5 Dongfeng Road, Zhengzhou, Henan 450002, China \\ E-mail: zhgy95@126.com
}

Received: February 1, 2012

Accepted: February 10, 2012

Published: June 1, 2012

doi:10.5539/ells.v2n2p100

URL: http://dx.doi.org/10.5539/ells.v2n2p100

\begin{abstract}
Economy principle is also called that of the least effort, which is pursued by human being in various activities due to the innate indolence. It aims at the maximum effect with the least input. It displays itself in each language in different ways. It is reflected in both static and dynamic respects of languages. This paper mainly focuses on the embodiment of economy principle in the English language from four aspects: phonetics/phonology, lexis, syntax and semantics.
\end{abstract}

Keywords: Economy principle, Embodiment, English language

\section{Introduction and Review}

"Economy" is a tenet or tendency shared by all living organisms and it is also referred to as the principle of the least effort. It means gain, thrift, less burden, and saving, which consists in tending towards the minimum amount of effort that is necessary to achieve the maximum result, so that nothing is wasted. That is, the maximum benefit and utility are achieved with the least possible input. The reason for that is indolence, which is one of the inherent attributes of human being. People follow and pursue the economy principle in performing various activities with the same objective: all activities are carried out most efficiently with the least possible cost in terms of energy. In short, all these are attributed to natural inertia of human being in physiology and psychology. Besides being a biological principle, this principle displays itself fully in linguistics as well. Linguistic economy principle is one of the generally recognized mechanisms, the objective of which is to save more time and energy by conveying more information with less effort. On the one hand, language is the tool by which people communicate with each other, so it must be a system with high efficiency. On the other hand, people follow the economy principle consciously or unconsciously in communicating with others. The reasons are as follows: first, the sounds the speech organs of human being can pronounce, the ability of human being in hearing and identifying sounds and people's memory are all limited; secondly, concise expressions can convey people's thoughts and feelings more rapidly than redundant, cumbrous ones; finally, language, as a tool of communication and getting to know about the world, should be easy to use.

The famous linguist Whitney noticed the role of economy principle in language changes, and held that human being is always managing (unconsciously in most cases) to "to make things easy to our organs of speech, to economize time and effort in the work of expression"(Whitney, 1877: 345). Sweet further pointed out two principles of economy in phonology: "(a) dropping of superfluous sounds; (b) ease of transition from one sound to another, which leads to convergence and assimilation..." (Sweet, 1888: 156) This phenomenon is due to inertia and indolence of the speech organs. An American linguist, Werner Leopold argued that there are two contradictory tendencies in any linguistic systems: "Linguistic development follows not one tendency, but two opposing ones: towards distinctness and towards economy. Either of these poles prevails, but both are present and alternately preponderant." (Leopold 1930: 102) That is, the tendency to distinctness is based on the fact that any speaker has, at any time, the overwhelming intention of being understood completely; tendency to economy is but the innate tendency of man, wisely given to him by nature, not to spend more energy on any effort than necessary. Valter Tauli put forward that linguistic evolution is determined by passive pressures and by five active driving forces: "(1) tendency towards clarity, (2) tendency towards ease or economy of effort, (3) emotional impulses, (4) aesthetic tendencies, (5) social impulses" (Tauli, 1958: 50). George Kingsley Zipf (1949) discovered that an inclination to economy is a criterion regulating any aspect of human behavior, which is governed by the principle of least effort. In the dynamic process of linguistic change, words are constantly being shortened, permuted, eliminated, borrowed and altered in meaning, but, thanks to the principle of least effort, equilibrium with a maximum of economy is always preserved. André 
Martinet (1955) provided a coherent definition of linguistic economy as the unstable balance between the needs of communication - which are always changing - and natural human inertia, two essential forces contributing to the optimization of the linguistic system. That is, the act of communication requires, on the one hand, clearness and precision, which multiply conspicuous units, and, on the other hand, a remarkable organic inertia, which produces effort relaxation, less numerous, less specific and more frequently occurring units, whose result is a hasty and careless expression. While inertia is a permanent, immutable component, man's communicative needs change constantly, so that the nature of this balance will be modified over time.

The economy principle is the common feature of all languages and it displays itself in different ways. This paper is designed to analyze the embodiment of economy principle in the English language in terms of phonology, lexis, syntax and semantics.

\section{Embodiment of Economy Principle in Phonetics/Phonology}

In the course of speech, two adjacent sounds, especially consonants within a word or between words may influence each other in pronunciation, which makes the two become similar or the same or a new sound. In this way, less effort is required in speech. This is just the economy principle in pronunciation, which is reflected in terms of assimilation, enclisis and ellipsis of some sounds.

\subsection{Sound Assimilation}

Sound assimilation is a common phonological process by which one sound becomes more like a nearby sound. This can occur either within a word or between words. In the course of continuous speech, two adjacent sounds often influence each other in pronunciation, and even are assimilated into a new sound which is different to either of them. It often occurs between two consonants. The main reason is to save effort. There are three types of assimilation: progressive assimilation, regressive assimilation and reciprocal assimilation. First, progressive assimilation is also known as perseveratory assimilation or left-to-right assimilation. It is a process in which a preceding sound has an effect on a following one. For example, the English plural is either $/ \mathrm{z} / \mathrm{or} / \mathrm{s} /$ when it occurs after a non-sibilant sound. The voicing feature is taken from the final consonant of the base. Another example "What's this?" is spoken as / 'wots ' $\mathrm{dis} /$, in which, the original voiced consonant $/ \mathrm{z} /$ is assimilated by the former sound $/ \mathrm{t} /$ into the voiceless consonant $/ \mathrm{s} /$. From these foregoing examples, we can feel that assimilated sounds cost less time and energy.

Regressive assimilation is a process in which a following sound has an effect on a preceding one. The preceding sound becomes more like the following sound because speech organs have got ready to pronounce the following sound before the preceding sound has been pronounced. It is also known as anticipatory assimilation, as the sound which changes anticipates the following sound in some way. For instance, "news" is read as /nju:z/, in which "s" is pronounced $/ \mathrm{z} /$ whereas " $\mathrm{s}$ " is pronounced /s/in the word "newspaper" because of the assimilation of the voiceless consonant $/ \mathrm{p} /$. Besides, when sounds $/ \mathrm{d} /, / \mathrm{t} /$ and $/ \mathrm{n} /$ are just before bilabial consonants $/ \mathrm{b} /, / \mathrm{p} / \mathrm{and} / \mathrm{m} /$ respectively, they will change accordingly. For example, in the actual process of speech "good boy" is often spoken as /'gub 'boi/ rather than /'gud 'boi/; "right place" is /'raip 'pleis/ rather than /'rait 'pleis/; "ten minutes" is /'tem 'minits/. Another example "I used to ..." is more often than not pronounced as /ai 'ju:st tu / rather than /ai 'ju:zd tu /, the reason of which is that the assimilated sound is easier to pronounce and needs less effort than unassimilated one.

Reciprocal assimilation, also called double assimilation, means that in the process of speech, two immediately adjacent sounds are influenced by each other and change into a third sound in order to save energy. Generally, these sounds are difficult to pronounce or may require more efforts when they are together, so the best way is that they are modified into a sound which is easier to pronounce. For instance, $/ \mathrm{t} /$ and $/ \mathrm{j} /$ are assimilated into $/ \mathrm{t} / \mathrm{j} / \mathrm{d} /$ and $/ \mathrm{j} /$ are pronounced $/ \mathrm{d} 3 /$ when they are not accented; $/ \mathrm{s} /$ and $/ \mathrm{j} /$ are spoken as $/ \mathrm{S} /$. Pay attention to assimilation of $/ \mathrm{t} /$ and $/ \mathrm{j} /$ and $/ \mathrm{d} /$ and $/ \mathrm{j} /$ in the following two sentences: "I'm glad to meet you."(/aim 'glæd to'mi:t $\mathrm{u} /$ ), and "Did you like it?"(/'did3u'laik it/).

\subsection{Enclisis}

In speech, words are not separated from each another by pausing or hesitating and generally the end of one word flows straight on to the beginning of the next. That is, pause only occurs at the end of a sentence or a sense group. Generally, in a sense group, the final consonant of one word is often linked to the beginning vowel of the immediately following word, which may sound better and be easier to speak. For instance, we write: Can I have a bit of egg? Nevertheless, we say it like this: Ca-nI-ha-va-bi-to-fegg? Whenever a word ending in a consonant sound is followed by a word beginning with a vowel sound, the consonant sound is linked to the vowel sound as if they were part of the same word.

\subsection{Sound Elision}

Sound elision is the omission of one or more sounds (such as a vowel, a consonant, or a whole syllable) in a word or 
phrase, producing a result that is easier for the speaker to pronounce, the main reason of which is human being's inertia or economy principle. It has two types: historical elision and contextual elision. Historical elision means that some sounds that were once pronounced but are no longer now, e.g. the pronunciation of "history" has changed from /'histrri/ to /'histri; "family" is pronounced as /'fæmli/ instead of /'fæmili/; "sovereign" is read as /'sovrin/ rather than /'sovərin/; "every" is spoken as /'evri/ instead of /'evəri/. Contextual elision is very common, especially in rapid speech. Sometimes several consonants are omitted. A common phenomenon is that sounds $/ \mathrm{t} / \mathrm{and} / \mathrm{d} /$ are frequently omitted when they are between other consonants. In the process of rapid speech, "just now" (/'d3/st 'nau /) has often become /'d3^s'nau /; "I want to ..." (/ai'wont tu/) is often spoken as /ai'won tu/; "a blind man" (/a 'blaind 'mæn /) is often /a 'blain 'mæn /; "a kind nurse" (/ə 'kaind 'nə: s/) is usually pronounced as /ə 'kain 'nə: s/. In this way, it sounds smoother and costs less energy.

\section{Embodiment of Economy Principle in Lexis}

Economy principle displays itself in English lexis. It is embodied in two aspects: one is the high degree of lexicalization and the other is rich abbreviations.

\subsection{High Degree of Lexicalization}

In linguistics, there are two kinds of expression for one concept or meaning: analytic expression and synthetic expression. The former is to use a phrase or clause or sentence to express the meaning or concept while the latter is to use one word to express the same. If two kinds of expression coexist in the same language, generally synthetic expression is preferred because it is more concise and economical. English is more lexicalized in expressing many concepts and is inclined to synthetic expressions.

\subsubsection{Rich Derivatives}

English is a synthetic language, which features rich affixes. In the English language, there are 337 prefixes and suffixes, which can be put before or after some words to create new words. For causative meaning, in addition to some causative verbs as "annoy", "embarrass", "satisfy", "confuse" etc., the English language has such prefixes and suffixes as "dis-", "en-", "de-" ,"-fy", "-ize", "-en" and so on to form words with causative meaning. Besides, the English language has many abstract nouns, which are commonly used in modern English. There are many affixes to form abstract nouns, e.g. -ness, -tion, -ity, -sion, -ence, -ment, -ship, -hood; trans-, intra-, ultra-, multi-, etc. Abstract nouns in the English language are very active and can express some complicated concepts or meanings which have to be expressed in analytic expressions, that is, phrases, clauses or sentences in other languages.

\subsubsection{Lexical Conversion}

Lexical conversion is the phenomenon of one word function directly converting to another function, not changing its form. The meaning is the same or extended a little. This is one commonly used method of word-building. That is to say, almost every word can be used as another part of speech without any change in form, e.g. to bottle (to put into a bottle), to pocket (to put into a pocket), to bicycle(to go by bicycle), to fuel (to provide fuel), to finance (to provide funds), to group (to make ... into groups) etc.. This is subject to the constraint of memorability, which can be the impetus for lexical conversion. In this way, people need not memorize too many new words in conveying information, which also complies with the economy principle. Compare the following pairs of sentences:

1a: They are planning to honeymoon in France.

1b: They are planning to spend their honeymoon in France.

2a: These birds are caged.

2b: These birds are kept in a cage.

3a: John buses to school every day.

3b: John goes to school by bus every day.

Comparatively, the first sentence of each pair is concise and preferred.

\subsection{Rich Abbreviations}

With the rapid speed of life and more information to convey, people manage to employ more economical methods of conveyance. One of the commonly used methods is to use more abbreviations, which is in conformity with the simple and economical psychology. Therefore, the increase of abbreviations is closely related to the economy principle in communication. In daily life, we often hear such abbreviations as "Ad (advertisement), Dept (Department), Lab (Laboratory), Max (Maximum), Min (Minimum), Vet (Veteran), "CPI (Consumer Price Index), GDP (Gross Domestic Product), CPU (Central Processing Unit), ATM (Automatic Teller Machine), GPS (Global Position System)" and so on. In addition, there are many abbreviations in different special fields. It is said that the 
English language has around 5000000 abbreviations. Using abbreviations saves a lot of time and energy for people.

\section{Embodiment of Economy Principle in Syntax}

Brevity is the soul of English. In English, lower levels of syntactic structures are preferred, which means that, if possible, words are used instead of phrases, and that phrases are used to replace clauses and that clauses may be used rather than sentences.

First, words are used instead of phrases. As mentioned above, English is highly lexicalized, so it is common that words rather than phrases are used. E.g.:

4a: The informative lecture impressed all of us.

$4 \mathrm{~b}$ : The lecture gave us a lot of information and made a deep impression on us.

5a: Our central teaching building is seaward.

5b: Our central teaching building is facing toward the sea.

Secondly, as we know, English is rich in abstract nouns. Therefore, it is common that noun phrases are used to express the meaning of clauses. E.g.:

6a: I saw the nurse's arrival.

6b: I saw that the nurse arrived.

\section{7a: The professor's cordial greeting was reassuring.}

7b: The professor greeted me in a warm and friendly way, which made me feel at ease.

Thirdly, in English, sentences are all SV-oriented, so relative pronouns and relative adverbs are quite active in introducing various clauses such as attributive clauses, adverbial clauses, and appositive clauses and so on. Of course, simple sentences can be used instead, but clauses are preferred out of economy. E.g.:

8a: I said nothing, which made him very angry.

\section{8b: I said nothing. That made him very angry.}

9a: I went back to the boat, which was sent drifting to the middle of the stream.

9b: I went back to the boat. The boat was sent drifting to the middle of the stream.

Comparatively, the first sentence of each pair is more authentic and most probably is the choice of native speakers.

\section{Embodiment of Economy Principle in Semantics}

\subsection{Polysemy}

English is often deemed as a language of high adaptability and plasticity. The meaning of English words is quite flexible, that is, rich and changeable. The meaning of words, with little independence, mainly depends on the context. There is a saying in English: "Words do not have meanings, people have meanings for words." For example, the verb "to get" can mean "procure" (I'll get the drinks), "become" (she got scared), "have" (I've got three dollars), and "understand" (I get it) etc.. The verb "kill" can mean "cause to die, or put to death intentionally or knowingly" (This man killed several people when he tried to rob a bank.), "cause the death of, without intention" (She was killed in the collision of three cars.), "be fatal"(Drunken driving kills.), "be the source of great pain for" (These new shoes are killing me!), "hit with so much force as to make a return impossible, in racket games" (She killed the ball.), "deprive of life" (AIDS has killed thousands in Africa), "drink down entirely" (She killed a bottle of brandy that night.), "mark for deletion, rub off, or erase"(kill these lines in the President's speech), "tire out completely" (The daily stress of her work is killing her.), "cause to cease operating" (kill the engine), and "destroy a vitally essential quality of or in" (Eating artichokes kills the taste of all other foods.) Perhaps the word in English with the most meanings is "set". Dictionaries give "set" around 120 meanings. The English language abounds with polysemic words with two, three or more meanings, including 'wood,' which means both part of a tree and a group of trees. Polysemy can reduce the increasing of new words to some extent, which relieves the burden of memory for English-speaking people.

\subsection{Common Use of Metaphors}

George Lakoff and Mark Johnson (1980) argue that metaphors are pervasive in everyday life. Metaphors are comparisons that show how two things that are not alike in most ways are similar in one important way. Languages appear and develop with the appearance and development of society. However, language development cannot synchronize with the changes in social life, which leads to the poverty of language. That is, we cannot create a new word for every newly appearing thing, phenomenon or mankind's experience, which results in the resort to existing 
language elements. Thus metaphors, which make up for the lexical gap and create many new expressions, appear accordingly. Metaphors are vivid and concise, and can convey some abstract and complicated meaning. We use metaphors so often that we are even not conscious of that we are using them.

There are two types of metaphorical expressions: metaphorical naming and metaphorical statement. Metaphorical naming provides vivid images with memorizing convenience. For instance, "bear market", "bull market" and "dogs and cats" in stock market can convey more information than the names themselves. Metaphorical statements generally implies rich meaning which can be inferred from the context and presuppositions, e.g. "All the world's a stage and men and women merely players."(Shakespeare, 1623: Act II, Scene VII) The world is described as a stage, which is the primary entity, and men and women are the subsidiary subjects who are a part of the stage. In daily life, metaphors are so ubiquitous that we are not aware of their existence. They are commonly used because they really convey more information than what they literally mean. In short, people unconsciously follow the economy principle.

\section{Conclusion}

Economy principle displays itself in many aspects of the English language, not only in static respect, but also in dynamic respect. This paper mainly focuses the former. Besides, it is embodied in both synchronic and diachronic aspects. All languages develop subject to the economy principle. Different languages have different methods of employing and displaying economy principle, which is the common objective of all language speakers.

\section{References}

Whitney, W. D. (1877). The Principle of Economy as a Phonetic Force. Transactions of the American Philological Association, Volume 3.

Sweet, H. (1888). A history of English sounds from the earliest period. Oxford: Clarendon Press.

Vendryes, J. (1939). Parler par économie. In Mélanges de linguistique offerts à Charles Bally. Genève: Georg et cie, s.a.

Leopold, W. (1930). Polarity in language. Curme volume of linguistics studies. Baltimore: Waverly Press.

Zipf, G. K. (1949). Human behavior and the principle of least effort. Cambridge: Addison-Wesley Press.

Tauli, V. (1958). The structural tendencies of languages. Helsinki: Suomalainen Tiedeakatemia.

Martinet, A. (1955). Economie des changements phonétiques traité de phonologie diachronique. Berne: Berne, A. Francke.

Lakoff, G., \& Mark, J. (1980). Metaphors we live by. Chicago: University of Chicago Press. 